\title{
Investigação do processo de corrosão causado pela polpa de bauxita em mineroduto de aço carbono
}

\author{
Investigation of the corrosive process \\ caused by pulp bauxite in \\ pipeline carbon steel
}

\author{
Marcelo Costa Santos ${ }^{1}$, Clairon Lima Pinheiro ${ }^{2}$, \\ José Carlos de Araújo Cardoso Filho ${ }^{3}$
}

\author{
${ }^{1}$ PRODERNA, UFPA - Rua Augusto Corrêa, 01, Guamá, Belém - Pará, Brasil \\ e-mail: marceloenqui@bol.com.br \\ ${ }^{2}$ Escola Superior de Tecnologia, UEA - Av. Darcy Vargas, 1200, Sala B10a Parque 10, Manaus - Amazonas, Brasil \\ e-mail: claironlp@yahoo.com.br \\ ${ }^{3}$ Faculdade de Engenharia Química, UFPA - Rua Augusto Corrêa, 01, Guamá, Belém - Pará, Brasil \\ e-mail: jc@ufpa.br
}

\begin{abstract}
RESUMO
O tempo de vida útil de um mineroduto depende de diversos fatores, dentre os quais aqueles relacionados ao processo de corrosão provocado pelo escoamento da polpa de minério. Nesse contexto, a corrosão do aço carbono API 5L-X70 foi investigada em meio de água do processo e polpa de bauxita $(5 \% \mathrm{~m} / \mathrm{v})$ utilizando técnicas eletroquímicas. Os resultados do potencial de circuito aberto $\left(\mathrm{E}_{\mathrm{OC}}\right)$, polarização e impedância eletroquímica (EIE) mostraram que a presença do minério de bauxita provocou mudanças no comportamento eletroquímico do meio quando comparados aos obtidos em água do processo na ausência do minério. Um aumento na taxa de corrosão do aço carbono foi observado pela presença da bauxita. A análise de superfície nos corpos de prova utilizando microscopia eletrônica de varredura (MEV) mostrou a formação de rachaduras nos óxidos presentes na superfície do metal, sendo esse fenômeno o responsável pelo aumento da corrosão do aço na presença da bauxita. A metodologia utilizada neste trabalho mostrou-se útil para a investigação de processos corrosivos em minerodutos e aplicável a outras situações onde polpas de minérios são escoadas em tubulações de aço.
\end{abstract}

Palavras-chave: Corrosão, bauxita, mineroduto, aço carbono.

\begin{abstract}
The corrosion caused by the ore slurry transported plays a fundamental role in the lifetime of a pipeline. Thus, the corrosion of API 5L-X70 carbon steel was investigated using process water and bauxite pulp (5\% w./v.) as solution and electrochemical techniques. The results of open circuit potential (OCP), polarization and electrochemical impedance spectroscopy (EIS) showed that presence of bauxite caused changes when it compared to water process results and the corrosion rate increased in the bauxite presence. The micrographs of specimens surface obtained by scanning electron microscopy (SEM) showed cracks formation in the oxide in the metal surface and this phenomenon may be responsible for increased corrosion in bauxite presence. The methodology described in this work show to be useful for the investigation of corrosion in pipelines.
\end{abstract}

Keywords: Corrosion, bauxite, pipeline, carbon steel.

\section{INTRODUÇÃO}

A utilização de dutos para o escoamento de petróleo, gás e minérios está aumentando consideravelmente nos países que produzem essas matérias-primas. Fatores como o baixo custo operacional e a segurança operacional apresentada no transporte destes fluídos são os responsáveis por esse crescimento [1,2]. Há um crescente desenvolvimento na região norte do Brasil de minerodutos que realizam o transporte de minérios sob a forma de polpa e o primeiro mineroduto utilizado para o transporte da bauxita (minério de alumínio cujos principais componentes são $\mathrm{Al}_{2} \mathrm{O}_{3}, \mathrm{SiO}_{2}, \mathrm{Fe}_{2} \mathrm{O}_{3}, \mathrm{TiO}_{2}$ ) está em operação no estado do Pará $[\underline{1}, \underline{3}, \underline{4}]$. 
A manutenção dos minerodutos está relacionada à agressividade do solo (corrosão externa) e à corrosão provocada na parte interna do mineroduto devido ao escoamento do fluido transportado. A taxa de corrosão na parede interna de um duto pode ser afetada pelo escoamento do fluido, proporcionando um fenômeno denominado de corrosão/erosão, que em casos práticos é o responsável pelo desgaste prematuro das paredes internas do duto [5].

O controle do processo corrosivo em ambos os meios é importante no sentido de evitar problemas ambientais e prejuízos financeiros devido a eventuais vazamentos [2]. Por esses motivos, o estudo do comportamento corrosivo entre o metal e o fluido transportado tem um papel relevante na estimativa da vida útil do mineroduto.

No transporte de fluidos em dutos ocorre o aparecimento de duas fases (líquido e gás) e no caso específico de minérios, o aparecimento de uma terceira fase (sólida) é observada devido à presença de partículas sólidas que se acumulam na parte inferior do duto, o que dificulta a investigação do processo de corrosão no interior de dutos [్,]].

O mineroduto de bauxita com aproximadamente $240 \mathrm{~km}$ de extensão, situado no sul do estado do Pará, por razões operacionais relacionadas à sedimentação de material no duto, alterna o transporte da polpa de bauxita com o da água retirada de uma fonte próxima à mina de Miltônia em Paragominas/PA. No destino final a referida água é utilizada nas etapas do processo de produção de alumina [3]].

Este trabalho apresenta como objetivo o estudo do comportamento eletroquímico na interface entre o aço carbono e a polpa de bauxita em condições aproximadas ao encontrado no mineroduto aqui citado, utilizando técnicas eletroquímicas de potencial de corrosão, polarização potenciodinâmica e espectroscopia de impedância eletroquímica. Outras técnicas de caracterização da superfície como microscopia eletrônica de varredura (MEV), análises por energia dispersiva de raios-X (EDX) e microscopia óptica (MO) foram utilizadas.

\section{MATERIAIS E MÉTODOS}

\subsection{Materiais}

O eletrodo de trabalho (ET) de aço carbono utilizado nos ensaios eletroquímicos (com área de $1,0 \mathrm{~cm}^{2}$ ) foi obtido de uma amostra retirada de um mineroduto utilizado no transporte da polpa de bauxita. A composição química do aço é apresentada na Tabela 1 e pode ser classificado como um aço carbono API 5L-X70.

Tabela 1: Composição química (\% massa) do corpo de prova de aço carbono

\begin{tabular}{c|c|c|c|c|c|c|c|c|c|c|c|c|c}
\hline \multicolumn{10}{c}{ ELEMENTOS (\% MASSA) } \\
\hline $\mathrm{Al}$ & $\mathrm{C}$ & $\mathrm{Cr}$ & $\mathrm{Cu}$ & $\mathrm{Mn}$ & $\mathrm{Mo}$ & $\mathrm{Nb}$ & $\mathrm{Ni}$ & $\mathrm{P}$ & $\mathrm{S}$ & $\mathrm{Si}$ & $\mathrm{Ti}$ & $\mathrm{V}$ & $\mathrm{Fe}$ \\
\hline 0,025 & 0,07 & 0,02 & 0,01 & 1,56 & 0,004 & 0,042 & 0,01 & 0,012 & 0,001 & 0,32 & 0,036 & 0,04 & 97,85 \\
\hline
\end{tabular}

A água do processo para a diluição do minério bauxita e a polpa de bauxita com o teor de $5 \%$ (m./v.) foram utilizadas como eletrólitos nos ensaios eletroquímicos realizados a $25^{\circ} \mathrm{C}$. A amostragem das mesmas ocorreu na mina Miltônia em Paragominas/PA.

A caracterização físico-química dos eletrólitos utilizados neste trabalho: Água do processo e a polpa de bauxita (5\% m./v.) é apresentada na Tabela 2. A concentração de bauxita no eletrólito foi tal que não ocorreu qualquer tipo de precipitado.

Tabela 2: Resultados das análises Físico-químicas

\begin{tabular}{|c|c|c|}
\hline \multirow[b]{2}{*}{ PARÂMETROS FÍSICO-QUÍMICOS } & \multicolumn{2}{|c|}{ ELETRÓLITOS } \\
\hline & ÁGUA & POLPA \\
\hline Temperatura $\left({ }^{\circ} \mathrm{C}\right)$ & 25,0 & 25,0 \\
\hline $\mathrm{pH}$ & 5,80 & 7,50 \\
\hline Sólidos totais dissolvidos (ppm) & 16,32 & 48,28 \\
\hline Condutividade $\left(\mu \mathrm{S} . \mathrm{cm}^{-1}\right)$ & 24,00 & 71,00 \\
\hline Dureza Ca (ppm) & 2,40 & 28,00 \\
\hline Alcalinidade (em ppm de $\mathrm{CaCO}_{3}$ ) & 3,50 & 7,10 \\
\hline O.D. (ppm) & 8,00 & 6,00 \\
\hline Cloretos (ppm) & 6,00 & 6,10 \\
\hline
\end{tabular}


A célula eletroquímica de três eletrodos consistiu de uma cuba eletrolítica de $500 \mathrm{~mL}$, um eletrodo de referência de calomelano saturado (ECS), uma rede de platina como contra eletrodo de $4,0 \mathrm{~cm}^{2}$ (CE) e o eletrodo de trabalho.

\subsection{Ensaios eletroquímicos}

As curvas de polarização potenciodinâmicas foram obtidas após a estabilização do $\mathrm{E}_{\mathrm{OC}}$, aplicando-se sobretensões anódicas e catódicas de 50,0 mV, com velocidade de varredura de 0,2 mV/s. As curvas de polarização foram obtidas através da técnica do eletrodo de disco rotativo (EDR) com a velocidade de rotação do disco de $1200 \mathrm{rpm}$.

Os ensaios de impedância eletroquímica foram realizados na faixa de freqüência entre $1,0 \mathrm{kHz}$ a $0,1 \mathrm{~Hz}$ e no potencial de circuito aberto, sendo feitas 10 leituras por década logarítmica com amplitude de tensão de $15,0 \mathrm{mV}$. Os ensaios eletroquímicos de polarização potenciodinâmica e impedância eletroquímica foram obtidos em duplicada; a obtenção e a análise dos dados foram obtidas com um Potenciostato / Galvanostato e o software ESA400, ambos da Gamry Instruments.

\subsection{Caracterização do Eletrodo de Trabalho (ET)}

A análise semiquantitativa de Fluorescência de raios x (FRX) do eletrodo de trabalho após os ensaios eletroquímicos foi obtida em um Espectrômetro, Axios Mineral da PANalytical. A análise morfológica do ET após os ensaios eletroquímicos foi feita utilizando um microscópico eletrônico de varredura Zeiss modelo LEO 1430.

\section{RESULTADOS E DISCUSSÕES}

O potencial de circuito aberto $\left(\mathrm{E}_{\mathrm{OC}}\right)$ em função do tempo para o aço carbono nos eletrólitos água e polpa é apresentado na Figura 1. O tempo de análise do $\mathrm{E}_{\mathrm{OC}}$ foi de 30 minutos em ambos os eletrólitos e temperatura ambiente.

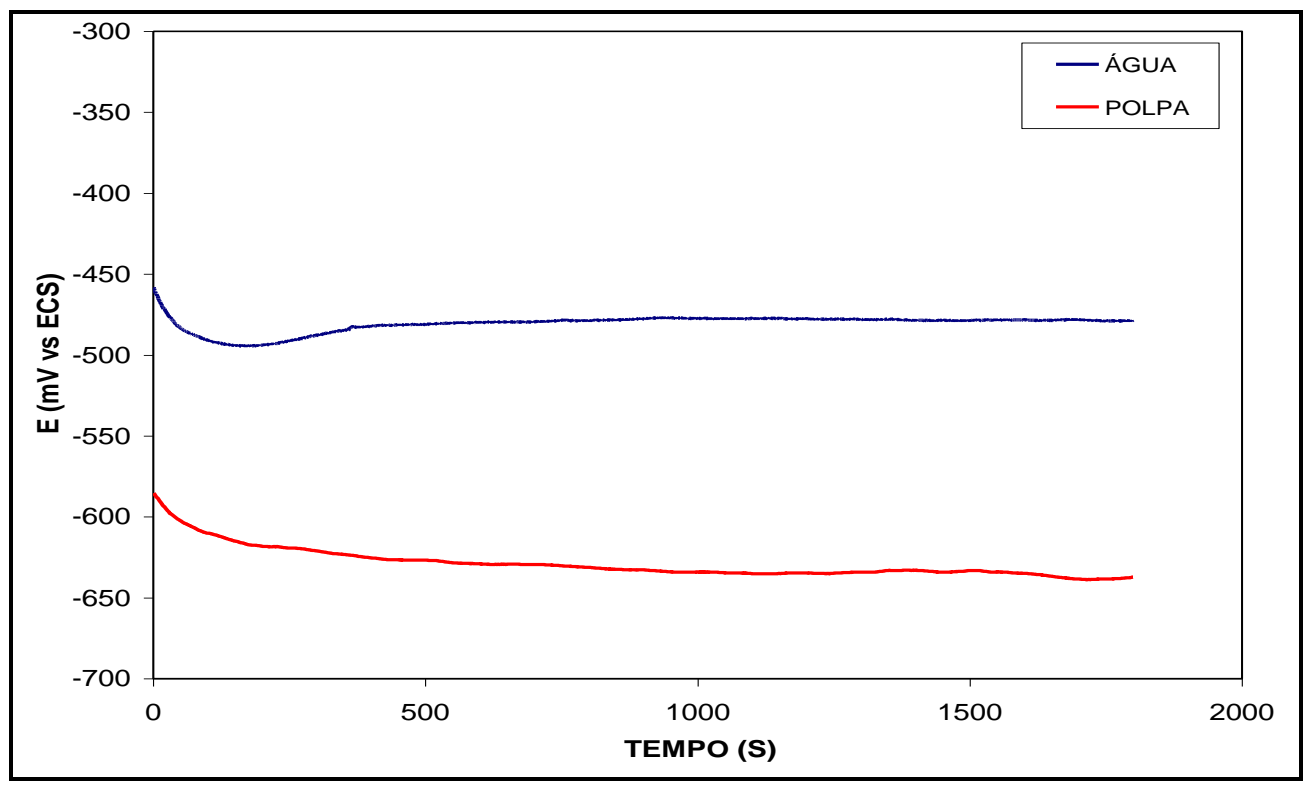

Figura 1: Potencial de circuito aberto do aço API 5L-X70 em água e polpa de bauxita $\left(25^{\circ} \mathrm{C}\right)$.

As curvas apresentadas na Figura 1 mostraram formas semelhantes, porém a presença da bauxita proporcionou um deslocamento de aproximadamente $130 \mathrm{mV}$ na direção da região catódica. Em ambas as curvas são observadas a diminuição do potencial no início do ensaio, seguido por uma tendência de estabilidade, após o período de 500 segundos do início do ensaio e após esse período foi notado uma estabilidade do potencial de corrosão, onde o aço carbono em presença de água apresenta um ECORR de aproximadamente $-430 \mathrm{mV}$ / ECS e, em presença da polpa de aproximadamente $-630 \mathrm{mV} / \mathrm{ECS}$.

As curvas de polarização potenciodinâmica para o aço API 5L-X70 em água e polpa da bauxita (5\% m./v.) são apresentadas na Figura 2. 


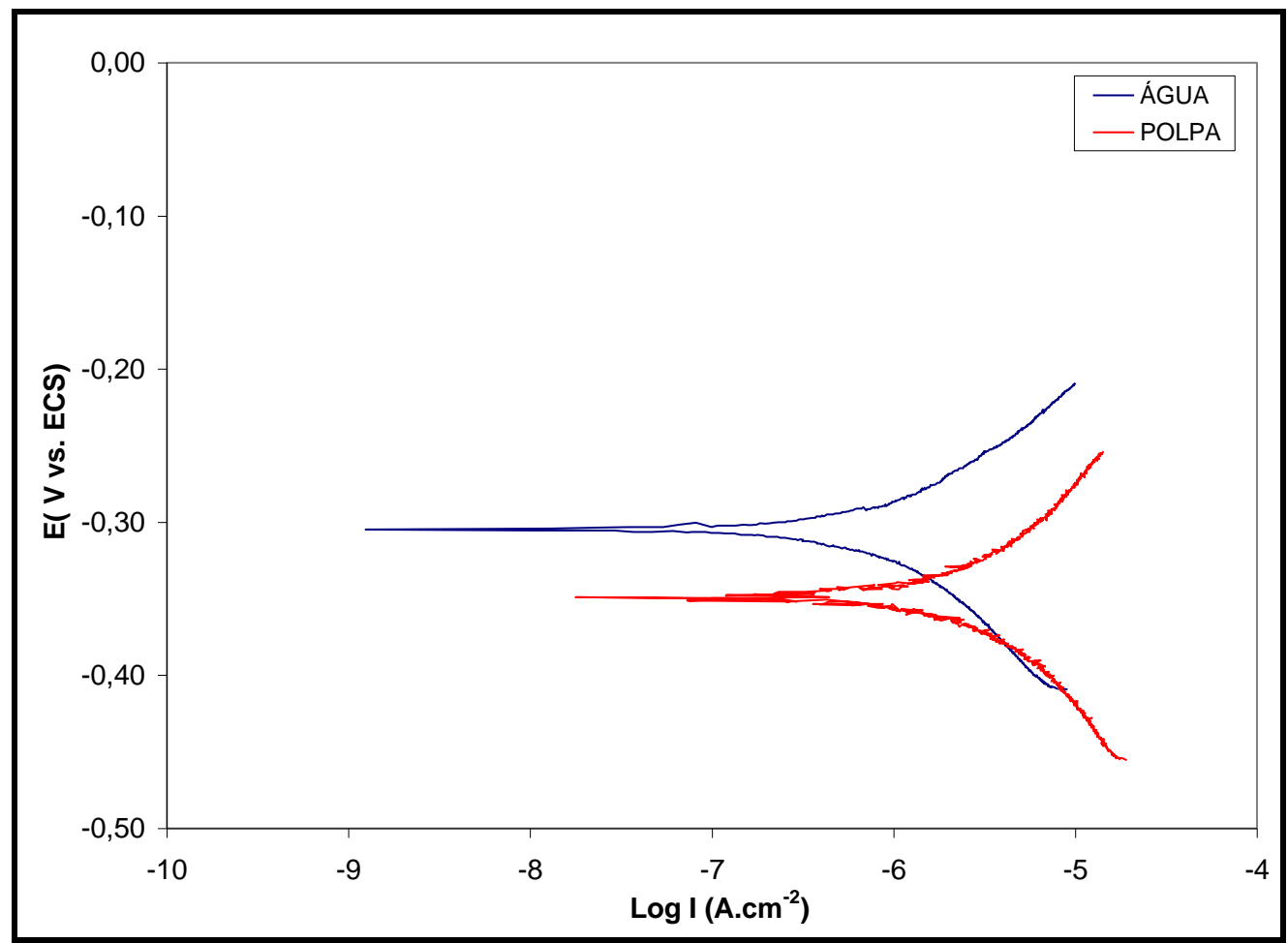

Figura 2: Curvas de polarização anódica e catódica do aço API 5L-X70 em água e polpa de bauxita $\left(25{ }^{0} \mathrm{C}\right)$.

Observa-se que a curva de polarização do aço carbono em meio à polpa de bauxita (Figura 2) é deslocada para uma região catódica em relação ao mesmo ensaio em água, fenômeno constatado na curva $\mathrm{E}_{\mathrm{OC}}$ versus tempo (Figura 1). Porém, as formas das curvas catódicas e anódicas não apresentam mudanças significativas com a presença da bauxita, indicando que o minério não modificou os mecanismos anódico e catódico. As taxas de corrosão determinadas na Figura 2 são apresentadas na Tabela 3.

Tabela 3: Densidades de correntes de corrosão $\left(I_{\text {corr }}\right)$ do aço API $5 \mathrm{~L}-\mathrm{X} 70$ em água e polpa de bauxita $\left(25^{\circ} \mathrm{C}\right)$.

\begin{tabular}{l|l|l}
\hline \multicolumn{1}{c|}{ MEIO } & \multicolumn{1}{c|}{ ÁGUA } & \multicolumn{1}{c}{ POLPA } \\
\hline Rotação $(\mathrm{rpm})$ & $I_{C O R R}\left(\mathrm{~A} / \mathrm{cm}^{2}\right)$ & $I_{C O R R}\left(\mathrm{~A} / \mathrm{cm}^{2}\right)$ \\
\hline 1200 & $6,8 \times 10^{-7}$ & $2,2 \times 10^{-6}$ \\
\hline
\end{tabular}

As curvas de polarização mostram que em meio à polpa de bauxita a densidade de corrente de corrosão $\left(\mathrm{I}_{\text {corr }}\right)$ é aproximadamente três vezes maior que na ausência da mesma (Tabela 3).

Na Figura 3 são apresentados os espectros de impedância eletroquímica nos meios de água e polpa de bauxita, decorridos 24 horas do início do ensaio. 


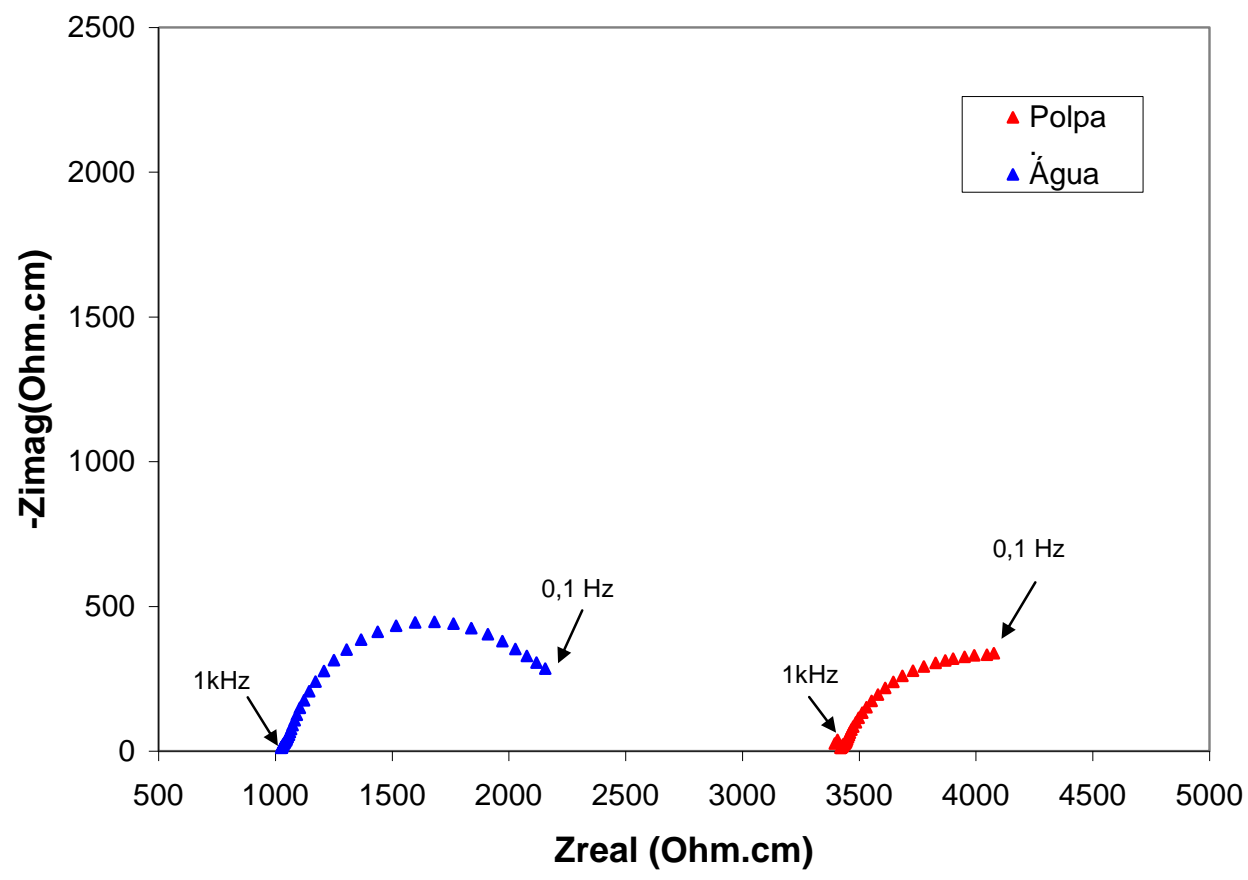

Figura 3: Diagramas de EIE aço API 5L-X70 em água e polpa de bauxita $\left(25^{\circ} \mathrm{C}\right)$, com 24 horas de imersão.

Os diagramas de Nyquist apresentados na Figura 3 mostraram arcos capacitivos com a forma de um semicírculo distorcido e que não interceptam o eixo " $Z_{\text {REAL }}$ ". Em meio à polpa de bauxita, ocorreu aumento da resistividade elétrica do eletrólito, o que é notado pelo deslocamento do diagrama para a região de maior impedância.

As resistências de polarização $\left(R_{P}\right)$ obtidas a partir dos diagramas de impedância eletroquímica são apresentadas na Tabela 4.

Tabela 4: Resistência de polarização $\left(\mathrm{R}_{\mathrm{P}}\right)$ do aço API $5 \mathrm{~L}-\mathrm{X} 70$ em água e polpa de bauxita $\left(25^{\circ} \mathrm{C}\right)$

\begin{tabular}{c|c}
\hline MEIO & $\mathbf{R}_{\mathbf{P}}$ (ohm.cm ${ }^{2}$ ) \\
\hline Água & 1290 \\
\hline Polpa & 980 \\
\hline
\end{tabular}

A redução do valor de RP na polpa de bauxita indica o aumento na taxa de corrosão do aço carbono no referido meio e está de acordo com o resultado encontrado no ensaio de polarização (Figura 2).

As reações eletroquímicas anódica (1) e catódica (2) que ocorrem na superfície do aço carbono podem ser representadas da seguinte forma [8,9]:

$$
\begin{aligned}
& \mathrm{Fe} \rightarrow \mathrm{Fe}^{2+}+2 e^{-} \\
& \mathrm{O}_{2}+2 \mathrm{H}_{2} \mathrm{O}+4 e^{-} \rightarrow 4 \mathrm{OH}^{-}
\end{aligned}
$$

Os óxidos formados na interface metal e eletrólito (Equações 3 e 4) têm um papel importante na taxa de corrosão, pois a densidade de corrente de corrosão tem como componente o processo de difusão das espécies $\mathrm{Fe}^{2+}$ e $\mathrm{O}_{2}$. É esperado que o produto de corrosão apresente $\mathrm{FeOOH}$ e $\mathrm{Fe}_{2} \mathrm{O}_{3}$.

$$
\begin{aligned}
& 2 \mathrm{Fe}(\mathrm{OH})_{2}+1 / 2 \mathrm{O}_{2} \rightarrow 2 \mathrm{FeOOH}+\mathrm{H}_{2} \mathrm{O} \\
& 2 \mathrm{FeOOH} \rightarrow \mathrm{Fe}_{2} \mathrm{O}_{3}+\mathrm{H}_{2} \mathrm{O}
\end{aligned}
$$

A camada de óxido formada na superfície do aço carbono após os ensaios eletroquímicos foi analisada por Fluorescência de raios-x e a composição química é apresentada na Tabela 5. 
Tabela 5: Composição química do produto de corrosão obtido através da técnica de FRX

\begin{tabular}{llllllllllllll}
\hline \multirow{2}{*}{ SOLUÇÃo } & \multicolumn{1}{c}{ ELEMENTOS (\% MASSA) } \\
\cline { 2 - 14 } & $\mathrm{Al}$ & $\mathrm{Ca}$ & $\mathrm{Cl}$ & $\mathrm{Fe}$ & $\mathrm{K}$ & $\mathrm{Mn}$ & $\mathrm{Na}$ & $\mathrm{Nb}$ & $\mathrm{O}$ & $\mathrm{P}$ & $\mathrm{Si}$ & $\mathrm{Ti}$ \\
Água & 0,04 & 0,18 & 0,16 & 67,90 & 0,03 & 0,78 & 0,26 & 0,03 & 30,24 & 0,20 & 0,36 & 0,01 \\
Polpa & 0,05 & 0,22 & 0,08 & 67,94 & 0,04 & 1,04 & 0,17 & 0,03 & 30,14 & 0,27 & 0,18 & 0,03 \\
\hline
\end{tabular}

A composição química do óxido formado quando o eletrodo de trabalho foi exposto à água de processo ficou próxima à composição química do mesmo exposto à polpa de bauxita. O ferro e o oxigênio representaram $97 \%$ da massa do óxido. O teor de alumínio foi praticamente constante em ambos os meios. Esse resultado mostra que a polpa de bauxita não interfere de forma significativa na composição química do produto de corrosão.

Após os ensaios eletroquímicos a superfície do aço carbono contendo o produto de corrosão formado foi analisada através da microscopia eletrônica de varredura (Figura 4).

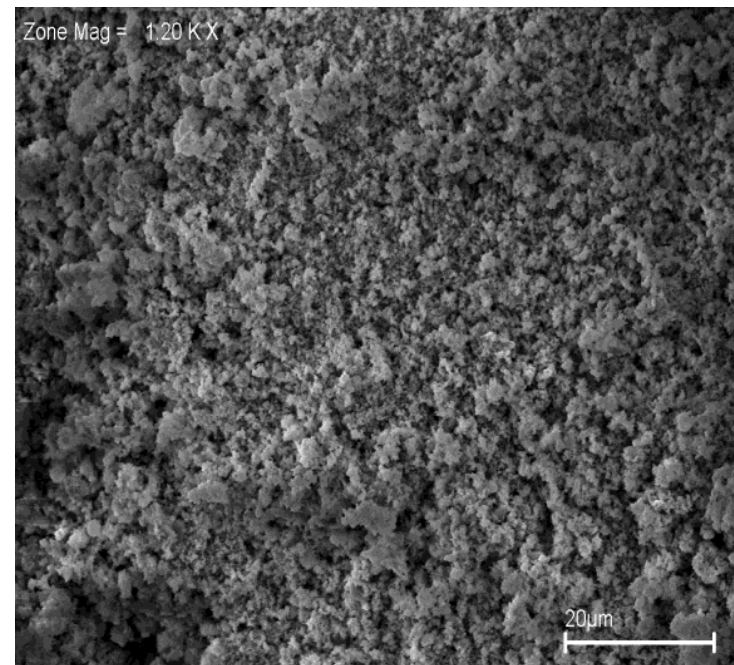

(a)

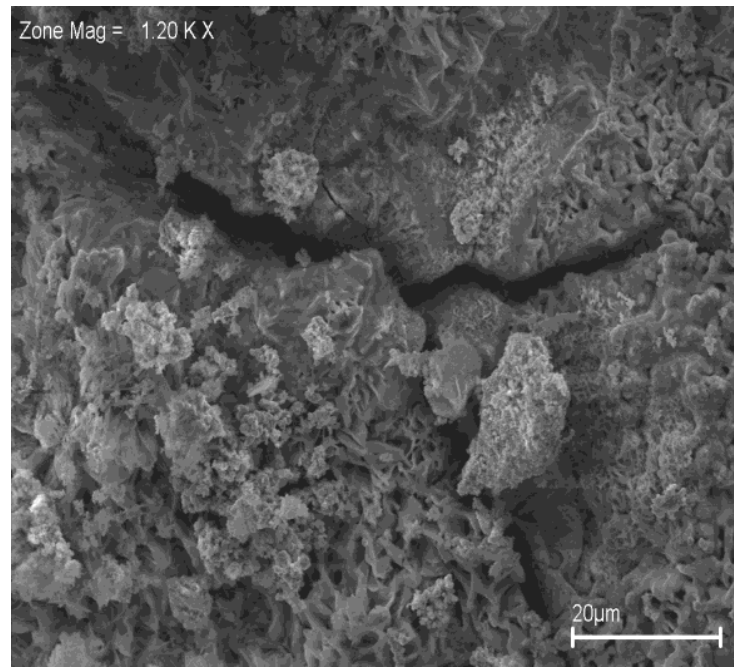

(b)

Figura 4: Micrografias do produto de corrosão (MEV) do aço API 5L-X70 em água (a) e na polpa de bauxita (b), com 24 horas de imersão $\left(25^{0} \mathrm{C}\right)$.

Uma morfologia bastante irregular foi observada no produto de corrosão nas micrografias referentes às figuras 4a e 4b. Porém, somente no óxido formado na presença da polpa de bauxita (Figura 4b), constatam-se rachaduras. As rachaduras observadas no produto de corrosão são as responsáveis pela diminuição da resistência a transferência de massa, proporcionando o aumento do fluxo de $\mathrm{O}_{2}$ na direção da superfície metálica. Esse fato pode explicar o aumento da corrosão do aço API 5L-X70 na presença da polpa de bauxita.

\section{CONCLUSÕES}

As técnicas eletroquímicas utilizadas na investigação do comportamento eletroquímico na interface aço-eletrólito mostraram o deslocamento do potencial de corrosão para a região catódica $(130 \mathrm{mV})$, quando o eletrólito utilizado foi à polpa de bauxita. Além disso, a exposição do aço neste eletrólito provocou um aumento na densidade da corrente de corrosão quando comparado ao meio contendo aço-água.

Os diagramas de espectroscopia de impedância eletroquímica indicaram que não há mudanças nos processos anódicos e catódicos, porém na presença da bauxita ocorreu a diminuição da resistência de polarização. Este último resultado corrobora com os ensaios de polarização eletroquímica.

A análise de superfície mostrou a formação de rachaduras somente na presença da polpa de bauxita, favorecendo a difusão das espécies químicas no interior do produto de corrosão e conseqüentemente aumentando a velocidade de corrosão do aço carbono API5L-X70. 


\section{AGRADECIMENTOS}

Os autores agradecem a mineradora VALE S.A. pelo fornecimento das amostras para os experimentos. Aos laboratórios de Raios-X e Microscopia eletrônica de varredura do Instituto de Geociências da UFPA.

\section{BIBLIOGRAFIA}

[1] NASCIMENTO, R. C. "Caracterização e determinação do comportamento de consolidação da polpa de bauxita", Revista Escola de Minas, v.63, n.2, pp. 325-329, 2010.

[2] SANTOS, M. C. Estudo do processo corrosivo na interface aço carbono / popa de buxita, Dissertação de M.Sc.,UFPA, Belém, PA, Brasil, 2011.

[3] OTHON, O., et al. "Caracterization of process in bauxite slurry pipeline", In: International Corrosion Meeting, $3^{\text {rd }}$, CD-ROM, Fortaleza, Brasil, Maio 2010.

[4] NECHITAILOV, A. P., SUSS, A. G., ZHILINA, T. I., et al., "New method of analyzing bauxites to determine their main components and impurities", Metallurgist, v. 52, n. 11-12, pp. 625-632, 2008

[5] RODRIGUES, J. R. P., FREIRE, C. M. A., BALLESTER, M., et al., "Monitoramento (on line) da Corrosão em Dutos por Impedância Eletroquímica". In: International Corrosion Meeting, $2^{\text {rd }}$, CD-ROM, Recife, Brasil, Maio 2008.

[6] LIMA, E., COSTA, R., CARDOSO FILHO, J. C., "Estudo do comportamento eletroquímico do aço carbono em água saturada com $\mathrm{CO}_{2}$ ”. In: XV Congresso Brasileiro de Engenharia Química, CD-ROM, Curitiba, Brasil, Maio 2004.

[7] ORAZEM, M. E., CARDOSO FILHO, J. C., TRIBOLLET, B., "Application of a Submerged Impinging Jet for Corrosion Studies: Development of Models for the Impedance Response", Electrochimica Acta, v. 46, pp. 3685-3698, 2001.

[8] ROBERGE, P. R., Handbook of Corrosion Engineering, 2 ed., New York, McGraw-Hill, 1999.

[9] BARD, A. J., STRATTMAN, M., FRANKEL, G. S., Encyclopedia of Electrochemical, Corrosion and Oxide Films, v. 4, New York, Wiley - VCH, 2003. 